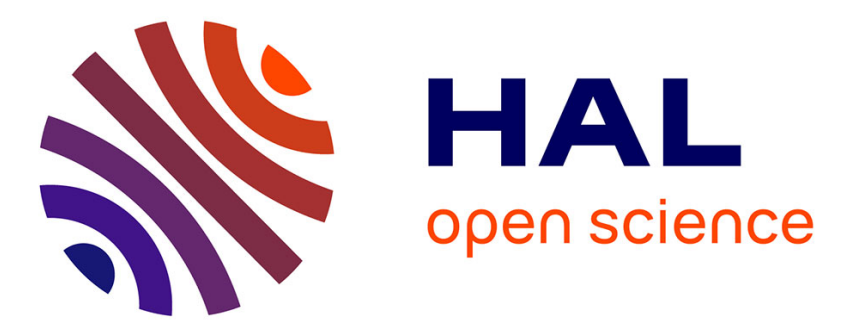

\title{
How do humans read robotics? The matter of the lexical ambiguity resolution
}

Céline Pieters, E Danblon, Jean-Paul Laumond

\section{To cite this version:}

Céline Pieters, E Danblon, Jean-Paul Laumond. How do humans read robotics? The matter of the lexical ambiguity resolution. IEEE/RSJ International Conference on Intelligent Robots and Systems (IROS 2018), Oct 2018, Madrid, Spain. 10.1109/IROS.2018.8594138 . hal-01983064

\section{HAL Id: hal-01983064 https://hal.laas.fr/hal-01983064}

Submitted on 16 Jan 2019

HAL is a multi-disciplinary open access archive for the deposit and dissemination of scientific research documents, whether they are published or not. The documents may come from teaching and research institutions in France or abroad, or from public or private research centers.
L'archive ouverte pluridisciplinaire HAL, est destinée au dépôt et à la diffusion de documents scientifiques de niveau recherche, publiés ou non, émanant des établissements d'enseignement et de recherche français ou étrangers, des laboratoires publics ou privés. 


\title{
How do humans read robotics?
}

\section{The matter of the lexical ambiguity resolution}

\author{
C. Pieters, E. Danblon, J.P. Laumond, LAAS-CNRS, ULB. ${ }^{1}$
}

\begin{abstract}
The words used to describe robotic performances include a degree of ambiguity that the human brain should solve without difficulty. However, the language used in -and about- robotics seems to escape from the ordinary processing of lexical ambiguity resolution. In this paper, we argue that there is no lack of an adequate language for robotics but that the lexicon at hand is forced by our representations. We investigate the main representational issues of the notions that express robotic actions and dispositions (i.e. behaviors).
\end{abstract}

I.

INTRODUCTION

People's growing interest towards robots lies in a shared wonder at a new technology that fascinates as much as it frightens. If the public has a craze for harder, better, faster, stronger and other superlative degree machines, the concern of the audience is not as obvious about the discipline of robotics itself. Many researchers in robotics regret that society tends to prefer to set out an imaginary journey in this matter rather than focusing on the technical (yet beautiful) functioning of this new technology. In a recent report [1], Rodney Brooks pinpoints "mistaken extrapolations, limited imagination, and other common mistakes that distract us from thinking more productively about the future". Facing this issue, the lack of technical practice within the educational system is often pointed out. Certainly, the place of techniques and technologies in teaching institutions could benefit from a re-examination. Yet, this argument is not sufficient to explain people's fear and fascination towards robotics. The public is indeed not the only one to seriously consider (or at least announce) future possibilities of development that have (hitherto) no scientific basis. The researchers who do so are obviously often severely criticized by their peers but they are also the ones who monopolize the public debate by introducing vaguenesses as a criteria of complexity and as a powerful sign for intellectual interest. It is therefore the responsibility of the roboticists to address concerns and controversies. In this perspective, the IEEE society recently launched a global initiative for ethical consideration [2] to better understand how society integrates a new technology.

The question of why machines challenge humans up to the point of being conceived as the next step of the natural evolution (in the most extreme case) is largely grasped by disciplinary fields such as philosophy, psychology, sociology or anthropology that describe this vast and complex phenomenon from a specific point of view. In this paper, we propose to engage a dialogue between linguistics, cognitive sciences, rhetoric and robotics in order to describe the role of language in our representations of robots. Indeed, less than focusing on the reasons why people are more possibly inclined to fictional interpretation even though they have access to scientific knowledge of robots functioning, we propose to analyse how discourses about robot technical achievements are processed. We aim at offering new leads on the way natural language about robotics is used and understood by society, including roboticists themselves.

Undoubtedly, roboticists must be included in this study since they are the primary people to be affected by this discursive question. First of all, roboticists are the ones to be solicited when global institutions (as the European Parliament) engage in robot regulations. Also, roboticists face the need of society to understand and approve their research projects in order to obtain financial support (at least within the public research system). Finally and as kinesiologist M. Latash notices [3], "having an adequate language (adequate set of notions and ideas) is a necessary prerequisite for the development of any area of science [...] It is much harder to formulate problems $[\ldots]$ in an exact way that allows for their unambiguous experimental testing than to solve them." Consequently, the problem of using the right words to describe robots functioning is a matter for roboticists.

The contribution of this paper is the highlight of the consequences of the semantic problem of effability on the the language used in robotics. Also, we specify the concepts of robot actions (e.g., move, go, climb, decide, recognize, talk) and robot dispositions (e.g., intelligence, autonomy, empathy) and their respective bond to ambiguity.

II.

ROBOTICS AND LANGUAGE

Within robotic literature, natural language is mainly seized as a research topic in studies that specifically investigate human-robot interactions. Conversely, the problem of the absence of an adequate language concerns the entire field of robotics.

\section{A. Natural language as a research topic in robotics}

On one hand, natural language is at the core of research in Computational linguistics (CL) and Natural-language

\footnotetext{
${ }^{1}$ This work is supported by the European Research Council Advanced Grant 340050 Actanthrope. J.P. Laumond is a CNRS director of research in robotics at LAAS, Toulouse, France (e-mail: jean-paul.laumond@laas.fr). E. Danblon is a FNRS professor of rhetoric at the Free University of Brussels, Belgium. (e-mail: emmanuelle.danblon@ulb.ac.be). C. Pieters is with the LAAS-CNRS and the National Institute of Applied Sciences (INSA), Toulouse, France. She is also with the Free University of Brussels and is a member of the Group or Rhetoric and Linguistic Argumentation (GRAL), Brussels, Belgium (e-mail: celine.pieters@laas.fr).
} 
processing (NLP) both fields having for outcome the improvement of robot skills in communication (and consequently in interaction between humans and robot, or between humans). It is generally addressed that CL strives to model the competence of native speakers using mostly probabilistic models, while NLP seeks to program computers in order to help users to navigate and process large quantities of information that already exist in text form. In particular, CL defines mathematically classes of linguistic representations and formal grammars in order to devise efficient algorithms for learning and production of language (see for instance [4]). As for NLP (e.g., [5]), it typically involves tasks related to syntax (the most common one consisting in automatic terminology extraction of relevant terms from a given corpus); to semantics (natural language understanding and generation, question answering, word sense disambiguation, etc.); to discourse (automatic summarization, discourse analysis which consists notably in recognition and classification of speech acts in a text); and finally, to speech (recognition and segmentation of sound clips or people speaking).

On the other hand and besides computer scientists' concern, natural language occurs within studies that focus on users' representations of robots (i.e. on mental images that are built when facing actual machines or by imagination). The methods used usually address the need to evaluate specific technologies in specific contexts and involve complementary fields such as cognitive psychology [6] or anthropology. As Gaudiello and Zibetti notice in [7], representation of people towards robots are mostly investigated through closed-question surveys, whilst the participants are asked to rate sentences expressing situations of interaction with robots, emotions in interactions with robots or the social influence of robots. Also, studies test users through semantic differential ratings (for instance, "mortal versus without definite lifespan" like in The Human Likeness Questionnaire [8]). Accordingly, natural language is a means in the current work of human-robot interaction (HRI) which, as K. Dautenhahn suggests [9], is characterized by heterogeneity, both in terms of methodologies and measurements used to study technologies and their impact. Either way, the participants in HRI surveys are invited to rate words and sentences carefully pre-defined by a strong psychological study.

In section III., we focus on how these words are processed and how the ambiguity is handled. We describe how the human brain selects one or another meaning in general and propose an explanation to its failing when it comes to robotic matters. However, before these considerations, we must enlighten the link between motion and action [10] and its consequences on language.

\section{$B$. The problem of the absence of an adequate language in robotics}

With the necessary (yet discussed) condition of considering robots as physical moving machines, one of the problems faced by the field of robotics seems to reflect ones found within studies of biological objects, namely the absence of an adequate language to formulate problems (a question largely described in [11]). Regarding this matter, I. Gelfand [12] showed that mathematical language is an ideal tool to fill a gap while it allows to discuss new scientific questions. Latash observes that "the successful scientific analysis of movement of inanimate objects has been based on an adequate language reflected in the apparatus of differential equations, which provided the basis for classical physics". However, despite mathematics, at least two problems still remain for biological systems: the simplest movement is effortfully describable, and "taking a biological system apart may not help in understanding of its functioning, unlike, for example, such man-made systems as a television or a computer". [3]

Movement therefore raises a cognitive problem that refers to the question of the effability of representations [13]. The principle of effability is mostly advocated as the idea that "natural language can express anything that can be thought. A natural language is supposedly capable of rendering the totality of our experience (mental or physical) and, consequently, able to express all our sensations, perceptions, abstractions up to the question of why is there Something instead of Nothing. It is true that no purely verbal language ever entirely achieves total effability: think of having to describe, in words alone, the smell of rosemary. We are always required to supplement language with ostentions, expressive gestures, and so-called 'tonemic' features. Nevertheless, of all semiotic systems, nothing rivals language in its effability. This is why almost all projects for a perfect language start with natural, verbal languages as their model." [14] Although effortful, nothing according to this principle seems to prevent the expression of motion in natural language. Nevertheless, movement is still ineffable in the sense that as motion is observed and its properties measured, the capture of the action in its wholeness is not entailed.

First of all, living organisms change with experience and react to perceivable external stimuli, making variability a characteristic of living beings' movements. Repeating a task may cause changes in the neural system involved in the production of motor actions associated with a given task. Also, neural signals produced in response of a perturbation induce changes in the activity of the muscles. Making conclusions from experimental observations that involve application of external forces and repetitive observations, thus implies various high precautions. Besides, Latash introduces motor control as the physics of the unobservable objects.

Secondly, as motion is described, the effect produced by the physical move on the observer remains elusive. Our assumption can be enlightened by the study of $\mathrm{M}$. Dominicy [15] about translation from a natural language to another. Despite a detailed comment, the translator does not transmit any data on a native English speaker's representation when reading and interpreting a sentence. A full description does not bridge the effect produced by the utterance. This problem lies in the representational dimension of language as something is irremediably lost in a translation even if semantics (in the technical sense of the terms) is preserved. ${ }^{2}$

\footnotetext{
2 Considering the utterance "This is not rocket surgery". The latter wording can be translated as "Ce n'est pas la mer à boire" in French or as "Dat is niet zo ingewikkeld" in Dutch for example, and it is possible to describe to a non-native english speaker how it is usually used in a conversation and to what it refers to: the expression "This is not rocket surgery" is a canonical idiom blend (as described in [16]) that combines two elements from idiomatic phrases. The two combined sentences are "This is not rocket science" and "This is not brain surgery", and the mix is supposed to create notably a humorous effect. If the effect can be described, it is not however transmitted within the translation.
} 
The same applies to a paraphrase in a unique language as "Tom is taller than Tim" is not equivalent to "Tim is smaller than Tom" in the representation of the reader. In this sense and by analogy, movement creates a cognitive and linguistic problem as it may prove to be difficult to represent, formulate and translate from biological to robotic language (and vice et versa).

Still, in order to discuss robotic matters and to give value to robots performances, the observers (whether they are specialists or laymen) have the need of a common lexicon that allows quick and efficient representations of robotic movements and actions. Consequently, robotics borrows (spontaneously or in a thoughtful way) various words that are usually used to describe living beings' body and mind. The machines are intelligent, autonomous, make decisions, learn, help users to complete a given task, are tired, bothered, willing or not, etc.

The agentive lexicon is particularly efficient and convenient to depict robotic actions and behaviors as they appear obvious for everyone. For instance, if we say that "the robot decides to go on the left", no one will picture a teleoperated robot. According to Aristotle and thereafter to the antique language theorists, the primary function of discourse is the enargeia, i.e. the rhetoric practice of making facts visible through language. This concept is usually translated from ancient Greek as "visibility" or "presence" since the discourse must show above all. Regarding this matter, R. Webb exposes that the bond between the notion of energeia -with an "e"- (movement, acting objects) and the notion of enargeia - with an "a"- (the process consisting in making facts visible through discourse) is far more important than just a simple morphological resemblance. [17] These two forms of presence refer to a powerful visibility.

Nonetheless, this lexicon is also commonly defined as ambiguous, if not misleading. Many roboticists blame the use of inadequacy of the language used in robotics.[1] The main reason for this judgement lies in the problem of effability of primitive actions. [18] The lexicon, borrowed to the world of living organisms, is seen as lacking in accurately representing the technical achievements and scientific problems of moving machines.

\section{LEXICAL AMBIGUITY RESOLUTION}

The agentive lexicon used to describe robot actions and behaviors achieves a useful function that consists in allowing human beings to feature objects (and the world in general) at their own level. Ironically, this same lexicon raises (or at least encourages) one's doubt about the adequate interpretation of a situation or discourse about robots. Intelligence, autonomy, learning, decision, intention,... Are these words some rhetorical figures (as metaphors or metonymies) or does their literal meaning reveal actual qualities of robots?

Various researchers of the team Gepetto (LAAS-CNRS) answered spontaneously to the question by saying that these words are -just- metaphors or some given images. ${ }^{3}$ As they mean to answer the question asked in a thoughtful way, we noticed that the methodological solution invoked by the roboticists corresponded to a philosophical approach that helps to rethink the latter notions and evaluate ones own opinion on the adequacy of this lexicon to robots. But, as this normative method imposes to define the notions before the debate could be engaged, it also lacks in questioning the hierarchy of values associated to the given notions. [19] (We discuss an alternative method where notions are clarified without however being defined in the section $V$. Perspectives).

Consequently, rather than engaging in the question of what these words mean, we suggest to firstly observe how humans shape their interpretation of robots' descriptions. Firstly, we focus on the problem of the lexical access during sentence comprehension in order to better apprehend the question of how humans usually solve ambiguity in language. Secondly, we show that the ambiguity within robotic language is likely to be of a specific nature and there is hopefully something to gain in understanding linguistic uses, rather than to reject, if not forbid.

\section{A. Lexical access during sentence comprehension}

In the late 70's, David Swinney reconsidered the effects of context during a sentence comprehension via an investigation on the process by which humans resolve lexical ambiguity. [20] Swinney first noticed that ambiguous words occur far more often than people realise. Also, he raised the fact that humans are excellent in lexical ambiguity resolution: people figure out which meaning is intended so naturally that they rarely notice any ambiguity. Swinney came to question how humans treat lexical ambiguity as follows: do people access all meanings of words at such moments, or only one meaning?

For the purpose of the investigation, subjects listened to pre-recorded sentences that contained ambiguous words. These words were equibiased, i.e. that there were 2 possible meanings for each ambiguous word and one meaning was not favored over the other in common speech. The subjects were informed that they would be tested on their comprehension of these sentences. Subjects were for instance presented with the sentence: "Rumor had it that, for years, the government building had been plagued with problems. The man was not surprised when he found several bugs in the corner of the room." In this case, the word "bugs" could mean "insects" as much as "surveillance". With a delay corresponding to 3 syllables from the auditory ambiguous word stimulus, either "ANT", or "SPY", or an unrelated word such as "SEW", or even a non-word, was flashed on a screen. The subjects were asked to decide, as quickly as possible, whether the string of letters formed a word or not. In the meanwhile, context conditions varied from no biasing context (as above) to strongly biased context, leading the listeners towards one meaning or another. For instance, "Rumor had it that, for years, the government building had been plagued with problems. The man was not surprised when he found several spiders, roaches and other bugs in the corner of the room."

\footnotetext{
3 As a brief anecdote, we asked various roboticists (PhD students, Post-Doc researchers, Directors of research) of the team Gepetto in the department of robotics at LAAS-CNRS, if the verb "to decide" in a sentence such as "The humanoid robot HRP-2 decides to pick the ball from the floor" is a rhetorical figure or if the robot HRP-2 takes literally the decision. The debate still goes on today. In order to answer to the question asked in a thoughtful way, some of them attempted to give their personal (although finest) definition for this ambiguous notion; what does "to decide" mean? (as they would also question: what is intelligence? What is autonomy? etc.),... while others asked for a dictionary.
} 
Swinney claimed that if a person activates both meanings of an equibiased ambiguous word simultaneously, the response times should be the same regardless of which meaning is primed by the stimulus. However, if one meaning is activated, then the response time should be faster for the priming of that meaning. As we see in Fig. 1., results indicated that subjects accessed multiple meanings for ambiguous words, even when faced with strong contexts that specified a single meaning. Swinney could conclude that both meanings of the ambiguous prime word were initially retrieved, and then only, the contextually inappropriate meaning was quickly discarded.

Word recognition is consequently modular, rather than interactive. Basically, ambiguity characterizes natural language, and humans are designed to treat efficiently this specificity.

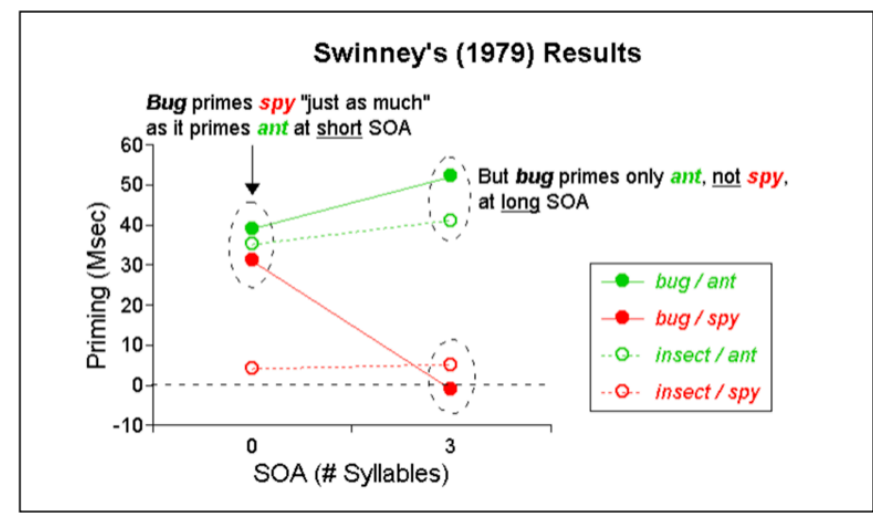

Fig. 1. The graph of Swinney's Results' shows that both "spy" or "ant" were primed at the same short time: as part of recognizing the word, multiple meanings are retrieved, even in conditions where there is a strongly biasing semantic context. At a slightly longer time (3 syllabes), the contextually inappropriate meaning (in this case, "spy") is discarded. (Lecture on lexical ambiguity resolution, Internal Psychology, University of Illinois, 22nd of September 2010.)

Let us now return to our subject of robotic language. We postulate that if the Swinney Test was to be taken with the ambigous lexicon used in robotics (for instance the word "intelligent"), the subjects of the experiment would first access both meanings (intelligent as "smart" like in "smartphone", i.e. as machinelike, and on the other hand, intelligent as "clever" or "wise", i.e. as lifelike). Then only, one or another meaning would be selected thanks to the context (for example, intelligent as machinelike would be selected in the following utterance: "I read an article about intelligent machines and I learned that the Kalman filter can continuously make available informations such as the position and velocity of an object, according to a series of measures including certainly errors of measurement").

There are at least two problems at the basis of this postulate. First of all, even if the context is biased in a way that it stimulates the selection of the machinelike meaning, one's interpretation is not necessarily shaped. The word "intelligent" does probably not sound more ambiguous for specialists in robotics as it is used in a sentence such as: "An intelligent machine can figure out the most efficient way to escape from a burning house". However, we can intuitively guess that it may cause a problem of interpretation to people who are not familiar with adopting a design stance towards robots (this notion was coined by D. Dennett [21]). The design stance allows to predict behavior based on how the agents are designed, but humans seem to spontaneously attribute intentionality to moving machines, as they naturally use an agentive lexicon (see the study of Heider and Simmel on apparent behavior [22]). People have the tendency to mobilize the intentional stance which allows to predict actions by assuming that they are pursuing goals. [23] If lexical ambiguity could be solved technically, the status of the robots is not necessarily cleared.

Secondly and especially, the utterance "intelligent" is not only machinelike -or- lifelike. According to the study of S. Turkle focusing on people's judgements about robots, it appears that as adults defined robots as machines, they also considered them "alive enough" to substitute people when they lack the ability to do something. [24] Gaudiello and Zibetti [7] comment this observation as follows: "after interacting with a robot, both adults and children seem to treat it as an intelligent entity, but intelligent in a unique way, which is different to the way that living or non-living entities are intelligent." Being alive seems to involve degrees instead of being a matter of all-or-nothing.

Why does the language used to outline robotics resist to the lexical ambiguity resolution? We suggest two hypotheses to describe this issue, conceding in the meanwhile a primary categorization of the robotic lexicon: we analyse the lexicon for robot dispositions, as well as the verbs of actions.

\section{B. Describing robot dispositions}

Regarding the lexicon borrowed from living organisms to describe robot behaviors (intelligent, autonomous, perhaps conscious,...), the concept of lexical ambiguity simply lacks in covering all aspects of the problem, as it does not allow to capture the whole complexity of this type of notions. The test of Swinney cannot be taken with this set of words as there is firstly a problem at the level of the lexical activation: each possible interpretation for a given word cannot be cleared in the first place. As we observed earlier, being alive seems to involve degrees instead of being a matter of all-or-nothing, and this statement is reflected in our inability to define the full range of meanings of a given word (as intelligent is not -just- "smart" versus "clever", but is a full spectrum that can be compared to a color palet).

This lexicon is in this sense not ambiguous, but coincides with the confused notions defined by Chaïm Perelman. A confused notion is a context-dependent notion that changes depending on socio-historical developments. [25] As so, it cannot be determined once and for all by the identification of a supposedly essence of the notion. [26] Such as "intelligence", "autonomy", "consciousness" or even "freedom", the meaning of confused notions is a matter of agreement and conventions. [27] The agreement is not only a matter of semantics but depends also on the ability of the orator to successfully justify a specific meaning to a given audience (in our case, the orator is obviously the roboticist).

\section{Describing robot actions}

While most of the verbs describing the actions of robots are not ambiguous (the robot moves, goes, climbs, walks, sees, speaks,...), others as the robot decides, learns, helps, looks, recognizes, knows, talks, judges,... may prove to be problematic as people must select the adequate interpretation. As humans experience multiple meanings access, the context is not always sufficient to discard the contextually inappropriate meaning. In this case, the veto on the contextually inadequate meaning does not apply, leaving 
the observer with multiple possibilities in terms of interpretation. For instance, the verb in "the robot decides to accomplish a task" remains with both possible machinelike and lifelike meanings.

The absence of veto on one given meaning is typical for discourses that mobilize massively a representational dimension which, as M. Dominicy specifies, is the case in poetry. Indeed, many poets widely use symbolic language (symbolic as a symbol articulates a second meaning with the prime), letting each reader with his own opinion on which interpretation should be preferred. Regarding this matter, Dominicy observes that "the human being is an interpretative animal; we rush to one interpretation, then argue with the persons who don't share it. Consideration should be rather given to the process involved in the production of the text, before choosing one interpretation". [28] In the case of the absence of veto, lexical ambiguity resolution thus becomes a question of symbolic language apprehension. In this sense, we assume that it passes from a matter of brain to an object of mind; as in the Swinney Test, the interpretation depends on an accurate (or not) brain activity (relative to On/Off), a missing veto means that opinions and arguments will be necessarily responsible to shape one's interpretation.

We pass from the fields of psycholinguistics and cognitive psychology to the art of persuasion, namely rhetoric.

IV.

\section{CONCLUSION}

While humans have the need to formulate thoughts, theories, concepts and ideas about robots, they also face a problem of effability within their representations of robotic actions and dispositions. The lexicon used to describe living organisms comes as a solution to this problem as it allows people (specialists and laymen) to picture machines from their own human's point of view. Paradoxically, the agentive lexicon proves to destabilize the understanding of the objects that it precisely defines. Regarding this matter, we formulated two hypotheses that set, at the same time, a primary categorization of the robotic lexicon.

The problem in the cognitive representation and consequently in the linguistic formulation, differs from one lexical category to another (see Table below). The lexicon of robot dispositions resists to one's interpretation because of its affiliation to the confused notions of Perelman. As these notions cannot be defined once and for all but depend on agreements and conventions, the cleared meanings (machinelike versus humanlike) are not appropriate to the notion itself. On the other hand, the verbs describing robot actions can be akin to symbolic language, typically used in poetry. As the veto does not apply, multiple meanings remain acceptable and humans stand with their opinions and (scientific) arguments as only tools to give sense to their observations. In both cases, we pass from a matter of cognitive psychology to an object of study for the field of rhetoric. The resulting interpretation will depend on the orator's efficiency and the audience's practical reasoning.

\begin{tabular}{|c|c|c|c|}
\hline \multirow[b]{2}{*}{ Lexicon } & \multicolumn{3}{|c|}{ Cognitive and linguistic problems of robotic language } \\
\hline & Examples & $\begin{array}{l}\text { Lexical } \\
\text { ambiguity } \\
\text { resolution }\end{array}$ & $\begin{array}{c}\text { Representational } \\
\text { problem } \\
\text { (ineffability) }\end{array}$ \\
\hline $\begin{array}{c}\text { Robot } \\
\text { dispositions }\end{array}$ & $\begin{array}{l}\text { Intelligent, } \\
\text { autonomous,... }\end{array}$ & $\begin{array}{l}\text { The concept } \\
\text { lacks in } \\
\text { covering the } \\
\text { problem in its } \\
\text { complexity }\end{array}$ & $\begin{array}{l}\text { Confused notions } \\
\text { (Perelman) }\end{array}$ \\
\hline \multirow[b]{2}{*}{$\begin{array}{l}\text { Robot } \\
\text { actions }\end{array}$} & $\begin{array}{l}\text { Move, go, climb, } \\
\text { see, speak,... }\end{array}$ & N.A. & / \\
\hline & $\begin{array}{l}\text { Decide, learn, } \\
\text { he } 1 \mathrm{p}, \quad 1 \text { o ok, } \\
\text { recognize, know, } \\
\text { talk, judge,... }\end{array}$ & Unsolved & $\begin{array}{l}\text { Symbolic } \\
\text { language (as in } \\
\text { poetry) }\end{array}$ \\
\hline
\end{tabular}

Facing this issue, why not systematically reject the traditional robotic language, if not forbid it? First of all, the history of language tells us that linguistic uses always impose themselves, even if opposed. Secondly, the assessment risks to be particularly negative in the long-term: on one hand, the roboticist fearing to influence inadequately the audience will cease to express himself, leaving society to its own fate. On the other hand, the researcher who will outright reject the use of this ambiguous lexicon, or will impose by force that a machine is -not-intelligent, will only encourage the development of conspiracy theories ("the roboticists hide results from society", "they program robots in order to manipulate the public and make people do what they want", etc.).

V.

\section{PERSPECTIVES}

In order to streamline our research, we consider the following questions;

- How does the technical knowledge intervene within the lexical ambiguity resolution? Does the exposure to technical contexts change the lexical ambiguity resolution? Consideration should be given to the question of the human brain's plasticity, and particularly to the study of Swinney, Love and Maas on the influence of language exposure on lexical language processing. [29]

- As a doubt raises about the adequate interpretation to prefer for a given robotic performance, the status of the words becomes unclear. Are these words some rhetorical figures (metaphors or metonymies)? The question of which rhetorical figure applies in each case deserves more attention. A metonymy would include the act of the roboticist in the meaning of the word linked to a robot action. If the lexicon can be proved and considered as metonymical, it could also become a precious medium to address legal responsibility matters in robotics.

- How can people apprehend such a lexicon as confused notions and symbolic language? Among the rhetorical apparatus, there is a practical tool to be explored, as it offers accurate solutions to apprehend such a lexicon. The dissociation of notions already proved its effectiveness in multiple fields where 
discourses are recognised as influent (politics, legal affairs, etc.). [19] It allows to shape notions within a debate with no need of disambiguation as a condition for argumentation. The dissociation of notions involves changes at the basis of argumentation and helps to remove incompatibilities that "arise out of the confrontation of one proposition with others [...]". [30] Also, Perelman and Olbrechts-Tyteca argue that "once the concepts have been dissociated and restructured, compromise tends to appear as the inescapable solution". The notions used in robotics must be investigated from such a rhetorical approach as we aim to grasp and clarify them for practical purposes.

- Finally, the lexicon of robot actions (decide, learn, know, etc.) deserves more attention. If a biased context that allows the veto to apply does not mean that we achieve to change a fictional representation about robots for a technical representation, it is still worth to work on building a lexical context that encourages the selection of a technical understanding. We postulate that the effectiveness of the context (on which the final interpretation (i.e. at long SOA) depends), has a relation to the distinctive theories of Pavlov and Bernstein about movements behavior. The controversy between Pavlov and Bernstein lies in the relative role of neural patterns in movement generation. It can be expressed as follows: a sensory feedback-based control of movements versus a central pattern generation. The Pavlov-Bernstein dispute is reflected in present discussions about motor programming versus perception-action coupling. [31] We assume that the interpretation of this specific set of words is an object of rhetoric, and that we can expect a radically different outcome if robot actions are considered under one or the other stream of thinking. We propose the following hypothesis: as movements and actions are described as being generated through both direct mechanical interactions and sensory signals (referring to Pavlov's theory), the context will be sufficient to activate the veto and discard the contextually inappropriate meaning of a given word (namely, the lifelike meaning). On the contrary, as movement generation is laid out in the light of Bernstein's theory (simply put, movements are controlled by cognition, mind,...), the meaning of the robotic lexicon will appear (even more) opaque to the observers.

As a final conclusion, we support the idea that robotics would first benefit from considering and elucidating linguistic and rhetorical issues. We hope to contribute to a better understanding of the notions that express robotic actions and dispositions.

\section{ACKNOWLEDGMENT}

The authors thank Prof. Marc Dominicy from the Free University of Brussels, for the useful discussions.

\section{REFERENCES}

1. R. Brooks, The Seven Deadly Sins of AI Predictions, MIT Technology Review, 2017
2. R. Chatila, K. Firth-Butterflied, J. C. Havens, K. Karachalios, The IEEE global initiative for ethical considerations in artificial intelligence and autonomous systems [standards]. IEEE Robotics and Automation Magazine, vol. 24(1), pp.110-110, 2017

3. M. L. Latash, Synergy, Oxford University Press, 2008

4. R. Hauser, Computational Linguistics and Talking Robots, Springer, 2011.

5. T. Brick, M. Scheutz, Incremental natural language processing for $H R I$, 2nd ACM/IEEE International Conference on Human-Robot Interaction (HRI), 2007

6. H.P. Jr. Kahn, A.L. Reichert, H.E. Gary et al., "The new ontological category hypothesis", Proceedings of Human-Robot Interaction (HRI), Lausanne, Switzerland, pp. 159-160, 2011

7. I. Gaudiello, E. Zibetti, Learning robotics with robotics, by robotics,: Educational robotics, Information systems, web and pervasive computing series, Human-Machine Interaction Set, Wiley-ISTE, 2016

8. C.C. Ho et MacDorman K. F., Revisiting the Uncanny Valley Theory: Developing and validating an alternative to the Godspeed indices, Computers in Human Behavior, vol. 26, pp. 1508-1518, 2010

9. K. Dautenhahn, "Methodologies and Themes of Human-Robot Interaction - A Growing Research Field," International Journal of Advanced Robotics Systems, vol.4, pp. 103-108, 2007.

10. J.P. Laumond, N. Mansard, J.B. Lasserre, Optimization as Motion Selection Principle in Robot Action, Communications of the ACM, vol. 58, no. 5, pp. 64-74, 2015.

11. J. L. Van Hemmen, "Biology and mathematics: A fruitful merger of two cultures", Biological cybernetics, vol. 97, pp. 1-3, 2007

12. I. M. Gelfand, "Two archetypes in the psychology of man", Nonlinear Science Today, vol. 1, pp. 11-16, 1991

13. J. J. Katz, J. A. Fodor, The Structure of a Semantic Theory, Language, Vol. 39, no. 2, pp. 170-210, 1963. in Proc. INTERMAG Conf., pp. 2.2-1-2.2-6, 1987

14. U. Eco, The Search for the Perfect Language, Wiley, 1995

15. M. Dominicy, Poétique de l'évocation, Classiques Garnier, coll. "Théorie de la littérature", 2011

16. J. C. Cutting, K. Bock, That's the way the cookie bounces: syntactic and semantic components of experimentally elicited idiom blends, Mem Cognit, vol. 25 (1), pp. 57-71, 1997

17. R. Webb, "Mémoire et imagination : les limites de l'enargeia dans la théorie rhétorique grecque", in C. Lévy and L. Pernot, Dire l'évidence, L'Harmattan, 1997

18. D. Davidson, Essays on Actions and Events: Philosophical Essays, Clarendon Press, 2001 [1980]

19. A. van Rees, Dissociation in Argumentative Discussions. A PragmaDialectical Perspective, vol 13. Argumentation Library, Springer, 2009

20. D. Swinney, "Lexical access during sentence comprehension: (Re) consideration of context effects", Journal of Verbal Learning and Verbal Behavior, vol. 18, pp. 645-659, 1979

21. D. Dennett, Consciousness Explained, The Penguin Press, 1992 [1991]

22. F. Heider, M. Simmel, "An Experimental Study of Apparent Behavior", American Journal of Psychology. vol. 57 (2), pp. 243-259, 1944

23. A. Wykowska A, E. Wiese, A. Prosser, H.J. Müller, Beliefs about the Minds of Others Influence How We Process Sensory Information, PLoS ONE, 9 (4), 2014

24. S. Turkle, The Second Self: Computers and the Human Spirit, MIT Press, 2005

25. Ch. Perelman, H.J. Berman, "The Use and Abuse of Confused Notions in Justice, Law and Argument", Studies, Epistemology, Logic, Methodology, and Philosophy of Science, vol 142., pp. 95-106, Springer, 1980

26. K. Popper, Conjectures and Refutations, Routledge, 1974 [1963]

27. E. Dupréel, Les sophistes, Ed. Griffon, 1948

28. M. Dominicy, Lecture on Poetics, Free University of Brussels, 20th of December 2017

29. D. Swinney, T. Love and E. Maas, "The Influence of Language Exposure on Lexical and Syntactic Language Processing", Experimental Psychology, vol. 50 (3), pp. 204-216, Hogrefe \& Huber Publishers, 2003

30. Ch. Perelman, L. Olbrechts-Tyteca, The New Rhetoric. A Treatise on Argumentation, University of Notre Dame Pess, 1991

31. Mark Latash, "Human Movements: Synergies, Stability, and Agility", Biomechanics of Anthropomorphic Systems, G. Venture, J.P. Laumond, B. Watier (Eds), STAR Series, Springer, (to appear), 2018. 